\title{
Comparison of the Microbiota of Snails (Helix aspersa) of Different Weights and Its Evolution over Time
}

\section{Carlos González-Núñez* and María A Calvo-Torras}

Departamento de sanidad y Anatomía Animal, Facultad de Veterinaria, Universidad Autónoma de Barcelona, Bellaterra (Barcelona), España, Spain

\begin{abstract}
Heliciculture produce snails that are eaten in many regions of Spain, especially in some areas where they are considered a delicacy. The fact of producing large snails would allow to maximize profits and for this reason to find the factors that regulate the weight of these mollusks is economically very interesting. In recent years, microbiota has been linked to weight in several species, including humans. The aim of this study was to evaluate the possible differences in the intestinal microbiota between snails (Helix aspersa) of different weights to establish the relationship between both. To do this, Aerobic Mesophilic, Lactic-Acid bacteria and Enterobacteriaceae counts were compared in stool samples from two groups of animals, distributed by weight. Furthermore, the evolution of the counts of these bacterial groups was observed from the waking from hibernation until the end of the study, after 22 days. The results showed no statistically significant differences between the two study groups in bacterial counts. In addition, no clear trend was observed in these counts during the course of the experiment. Additional studies could explain the differences found in this study compared with what is found in other papers.
\end{abstract}

Keywords: Heliciculture; Helix aspersa; Hibernation; Intestinal microbiota; Weight

\section{Introduction}

Heliciculture, or snail farming, can be defined as the activity that includes land snails husbandry under conditions controlled by man, during the whole life cycle, to its gastronomic consumption (Arietti DG (http://nulan.mdp.edu.ar)).

Eating snails is deeply rooted in some areas of the country where this animal is considered a real delicacy. Although there is little data about snail commerce, it is expected that its demand growth in next years, especially thanks to the efforts to meet the current food legislation which is done with the objective of increasing product quality and safety.

In the Heliciculture, as in all animal production systems, one of the most interesting parameters to improve is the weight of the snails, as their sale is made based on it. Getting bigger snails, if the quality is maintained, ensures greater benefits to the farmer if other production parameters, such as conversion rate, are constant. Therefore, to find the factors that influence weight gain, as well as the utilization of nutrients from the diet, could allow its manipulation to maximize profits.

In recent years, many studies have linked the intestinal microbiota with increased weight in several animal species, including humans. Those studies have shown that the mere presence of the gut microbiota is able to increase the weight of the animals, mainly through increased caloric diet extraction [1-3]. From this finding, numerous studies have been conducted to try to characterize the intestinal microbiota of animals with a higher weight, to assess whether there were significant differences between the phylotypes present in these animals and those of normal weight. Most of them have found that the intestinal microbiota of overweight animals were different than microbiota of normal animals [4-8].

The aim of this work was to study the intestinal microbiota of snails of different sizes to see if there were differences in the count of some bacterial groups when compared to each other. Moreover, as these snails had just come out of hibernation at the beginning of the experiment, evolution of the microbiota was also studied.

\section{Material and Methods}

For the study, snails of the specie Helix aspersa Müller (Figure 1A) from Cal Jep's farm (Castellfollit del Boix, Barcelona) were used. They had been in a state of hibernation for four months without eating. Two days before starting the study, animals were weighed and divided into two groups, large $(\mathrm{G})(6.629 \mathrm{~g} \pm 0.8537 \mathrm{~g})$ and small $(\mathrm{P})(3.845 \mathrm{~g} \pm$ $0.882 \mathrm{~g}$ ), depending on their weight. Thereupon, they were awakened and kept in four containers (two for $\mathrm{G}$ and two for $\mathrm{P}$ groups) so they had room to move (Figure 1B). A total of 17 snails, 11 small and 6 large, were used and were fed ad libitum with feed used on their farm. The water was provided twice daily using sprays.

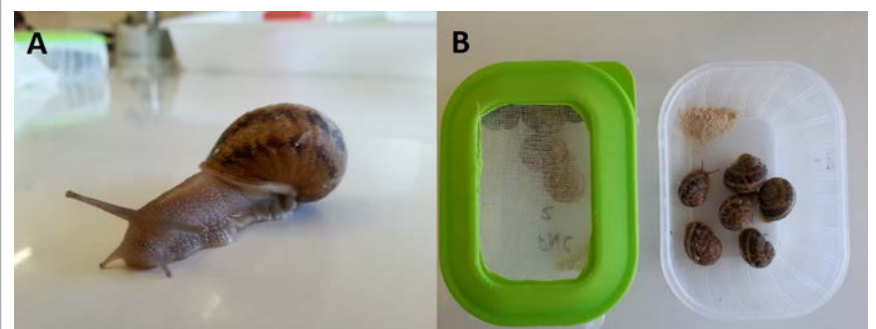

Figure 1: Helix aspersa Müller was the specie of snail used in this study (A). Container where snails where kept during the study (B).

\begin{abstract}
*Corresponding author: Carlos González-Núñez, Departamento de sanidad y Anatomía Animal, Facultad de Veterinaria, Universidad Autónoma de Barcelona, Bellaterra (Barcelona), España, Spain, Tel: +34 722 220274; E-mail: carlosgonznun@gmail.com
\end{abstract}

Received September 25, 2014; Accepted January 28, 2015; Published January 30,2015

Citation: Núñez CG, Torras MAC (2015) Comparison of the Microbiota of Snails (Helix aspersa) of Different Weights and Its Evolution over Time. J Veterinar Sci Technol 6: 216. doi:10.4172/2157-7579.1000216

Copyright: @ 2015 Núñez CG, et al. This is an open-access article distributed under the terms of the Creative Commons Attribution License, which permits unrestricted use, distribution, and reproduction in any medium, provided the original author and source are credited. 
Citation: Núñez CG, Torras MAC (2015) Comparison of the Microbiota of Snails (Helix aspersa) of Different Weights and Its Evolution over Time. J Veterinar Sci Technol 6: 216. doi:10.4172/2157-7579.1000216

Page 2 of 3

Sampling of feces was performed every 3-4 days during the 22 days of the study, obtaining only the excretions of the day in which they were processed. The day when the first sampling was obtained was considered as the Day 1. For this, 24 hours before sampling, the container where snails were living was cleaned in order to avoid contamination with the feces of the previous days. It was considered as the unit of study the whole $\mathrm{G}$ and $\mathrm{P}$ groups due to the difficulty of knowing which snail had excreted the excrements. Feces were collected in a sterile pot and resuspended in sterile Ringer $1 / 4$. Subsequently, a serial dilution was made to inoculate the agar plates.

For comparison of the microbiota present in both groups, colonyforming units (CFU) were counted after inoculation of plates of Trypticase Soy Agar (TSA) for Mesophilic Aerobes; Man-RogosaSharpe (MRS) for Lactic-Acid bacteria; MacConkey Agar to determine Enterobacteriaceae; Tryptone Sulfite Neomycin (TSN) for sulphitereducing clostridia; and Sulfite-Polymyxin Sulfadiazine (SPS) for Clostridium perfringens. MacConkey and TSA were incubated for 24 \pm 2 hours at $37^{\circ} \mathrm{C}$, MRS agar for $48 \pm 2$ hours at $37^{\circ} \mathrm{C}$ with $5 \% \mathrm{CO}_{2}$, and TSN and SPS for $48 \pm 2$ hours at $37^{\circ} \mathrm{C}$, in anaerobiosis conditions.

\section{Results}

\section{Differences between groups}

When the microbiota of the G and P group was compared using a Student's t-test, no significant differences were found between counts of Aerobic mesophilic bacteria $(\mathrm{P}=0.423)$, Lactic-Acid bacteria $(\mathrm{P}=0.205)$ and Enterobacteriaceae $(\mathrm{P}=0.632)$.

\section{Evolution of microbiota}

The level of Aerobic Mesophilic bacteria in both large and small snails was stabilized from Day 8 of the study on. In the case of large snails, Aerobic Mesophilic bacteria began presenting a relatively low concentration in feces but then they were increased until a level where they were kept constant. Meanwhile, in small snails occurred the opposite: Aerobic Mesophilic bacteria increased at first but then they decreased until they were stabilized. In the case of Lactic-Acid bacteria it was observed a different behavior. In large snails there was a slow but progressive increase from the start of the study to the end, but from Day 18 on the levels of these bacteria were stabilized. In small snails there was a reduction of almost one Log in Lactic-Acid bacteria in the first days of the study. However, the levels were increased slowly to reach the initial value. In the case of Enterobacteriaceae, levels were somewhat erratic in both groups with increases and decreases of the concentration of these microorganisms, although these changes were not significant. All data obtained allows to characterize the microbiota of these animals as fairly stable (Figure 2). There was no growth of sulfite-reducing bacteria and C. perfringens at any time of the study.

On the other hand, the correlation between the different study groups was also calculated but no significant relationship was observed between them $(\mathrm{P}>0.05)$.

\section{Discussion}

\section{Differences between groups}

The findings of this study show no significant differences between the microbiota of snails of different weight. This is consistent with findings in some articles $[9,10]$, but differs from the results of most studies [4-8]. There are several considerations to take into account that might explain these differences. These studies are assessing pathological conditions such as overweight and obesity. In the snails of this study the microbiota associated with weight was assessed but without going into the possibility that these animals may suffer these conditions. Thus it is very likely that the snails were completely healthy and weight differences were due only to interindividual variations that occur in a normal population. However, some of these papers also correlated microbiota with body weight, not with pathological states.

Therefore, there must be other differences between this study and others to explain the different results. Perhaps the answer lies in the species tested. The growth in mice, pigs or humans, species studied in the papers already cited, is much slower than the growth of the snails, which can double their weight in a few days. Increasing these differences between species there is the fact that snails come from a

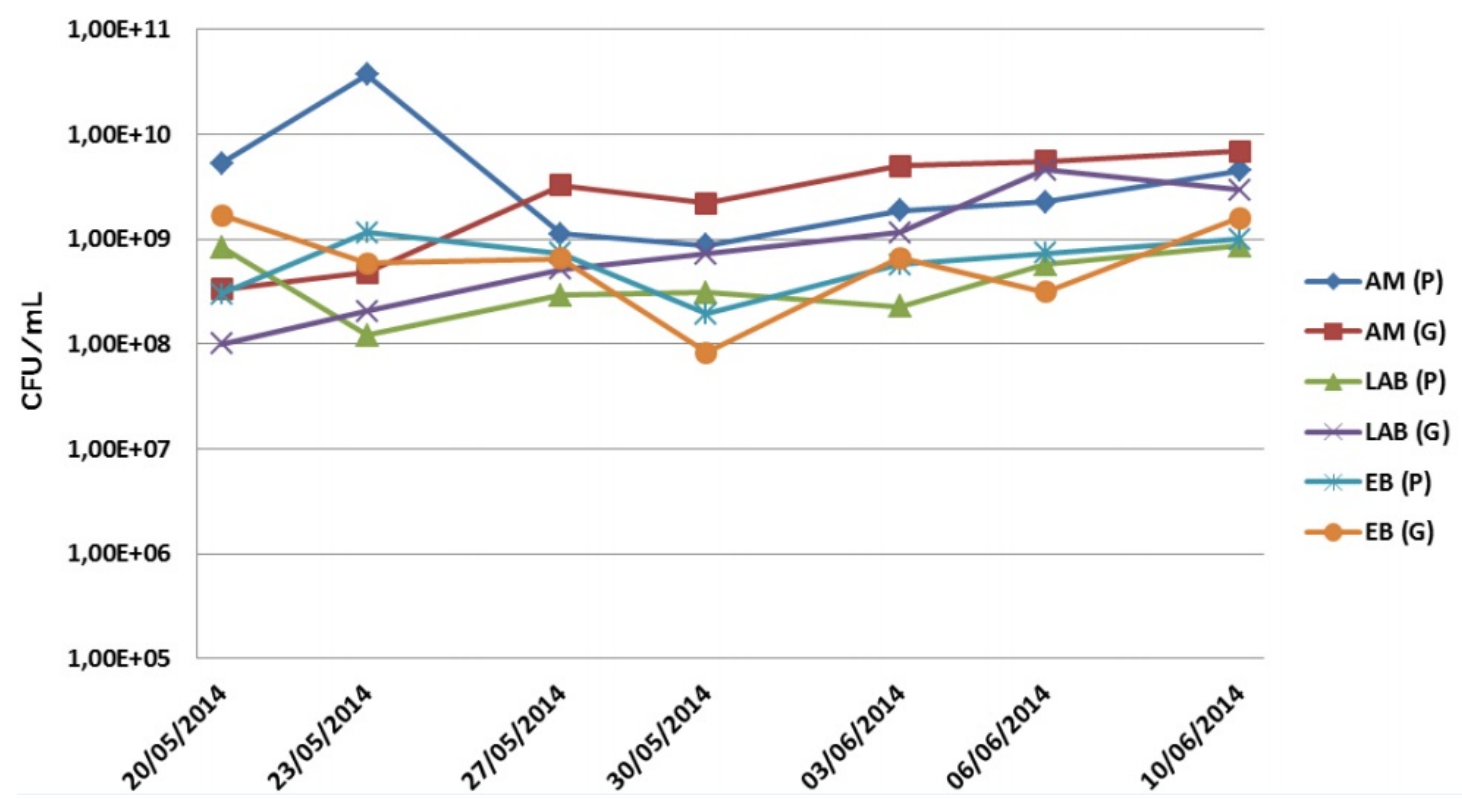

Figure 2: Evolution of microbiota throughout time. Abbreviations: AM (Aerobic Mesophilic), LAB (Lactic Acid Bacteria) and EB (Enterobacteriaceae) 
farm that has selected them over time. Bacteria have evolved over the years along with the species that host them, establishing a close relationship between both. The pressure exerted by human selection may have diluted the effects of the microbiota on the weight, which would not be able to adapt to the rapid growth of the snails.

Another explanation could be that there were differences between species in the mechanisms involved in weight gain due to microbiota. Several molecules have been related with the increase of body mass in animals and humans, as G protein-coupled receptor GPR41 and GPR43 (both activated by short chain fatty acids), CD14 (activated by lipopolysaccharides), Toll-like receptor 5, Fasting induced adipocyte factor (FIAF) and AMP-activated protein kinase (AMPK), but it is unknown if Helix aspersa is capable of expressing such proteins or if they are implicated in weight gain in these animals [11,12].

Although there is no difference between large and small snails in the bacterial groups studied, it is possible that differences in other taxonomic levels are given. In the aforementioned papers [4-8] phylotypes were assessed at the level of phylum, class, genus or species, so it would be necessary to take other more detailed studies to compare them in a more reliable way.

Finally, it must be considered the possibility that there are actually no differences between the microbiota of both groups of snails and that weight variations are due to other environmental and/or genetic factors.

\section{Evolution of microbiota}

The snails began the study just after waking up from hibernation, when they had been four months without eating. One of the most important factors in the modulation of the microbiota is diet. When the snails are in this state, microorganisms receive much less nutrients to grow, so microbial community and interactions between hos $t$ and microbiota can be altered [13]. Furthermore, it has been observed that during hibernation there are deep changes in the intestinal immune system of ground squirrels, which may affect the intestinal microbiota modulation [14]. Some studies have shown that during hibernation a decrease in diversity and number of species occurs, thus generating a very different microbiota in comparison with active animals $[13,15]$.

Although these studies are not comparable with this one due to differences in methodology, in species used or in the phylotypes evaluated, in the present study no large variations between the intestinal microbiota of snails just after waking up and snails of the end of the study were observed.

The only bacteria that showed a steady increase from the beginning to the end of the experiment were Lactic Acid and Aerobic Mesophilic bacteria of the G group. All the others, even with the small variations between different days of the study, showed no clear trend, demonstrating the stability of the microbiota of these mollusks.

\section{Conclusions}

It has been shown that large snails, in comparison with small, don't have higher counts of Aerobic Mesophilic bacteria, Lactic-Acid bacteria and Enterobacteriaceae, in contrast to the information found in the literature about what occurs in other species.

Microbiota, contrary to what could be expected considering the fact that the snails had just come out of hibernation, showed no significant differences between the start and the end of study.

The comparison between the results obtained in this study and those published in the literature should be taken with caution. The differences between the bacterial groups studied do not allow the comparison in an outright way, so it would be interesting to perform new experiments to evaluate other taxa.

\section{References}

1. Bäckhed F, Ding H, Wang T, Hooper LV, Koh GY, et al. (2004) The gut microbiota as an environmental factor that regulates fat storage. Proc Nat Acad Sci USA 101: 15718-15723.

2. Turnbaugh PJ, Ley RE, Mahowald MA, Magrini V, Mardis ER, et al. (2006) An obesity-associated gut microbiome with increased capacity for energy harvest. Nature 444: 1027-1031.

3. Turnbaugh PJ, Hamady M, Yatsunenko T, Cantarel BL, Duncan A, et al. (2009) A core gut microbiome in obese and lean twins. Nature 457: 480-484.

4. Ley RE, Bäckhed F, Turnbaugh P, Lozupone CA, Knight RD, et al. (2005) Obesity alters gut microbial ecology. Proc Natl Acad Sci USA 102: 1107011075.

5. Turnbaugh PJ, Bäckhed F, Fulton L, Gordon JI (2008) Diet-induced obesity is linked to marked but reversible alterations in the mouse distal gut microbiome. Cell Host Microbe 3: 213-223.

6. Million M, Maraninchi M, Henry M, Armougom F, Richet $\mathrm{H}$, et al. (2012) Obesityassociated gut microbiota is enriched in Lactobacillus reuteri and depleted in Bifidobacterium animalis and Methanobrevibacter smithii. Int $\mathrm{J}$ Obes (Lond) 36: $817-825$

7. Pedersen R, Andersen AD, Mølbak L, Stagsted J, Boye M (2013) Changes in the gut microbiota of cloned and non-cloned control pigs during development of obesity: gut microbiota during development of obesity in cloned pigs. BMC Microbiol 13: 30 .

8. Verdam FJ, Fuentes S, de Jonge C, Zoetendal EG, Erbil R, et al. (2013) Human intestinal microbiota composition is associated with local and systemic inflammation in obesity. Obesity (Silver Spring) 21: E607-E115

9. Ley RE, Turnbaugh PJ, Klein S, Gordon JI (2006) Microbial ecology: human gut microbes associated with obesity. Nature 444: 1022-1023.

10. Duncan SH, Lobley GE, Holtrop G, Ince J, Johnstone AM, et al. (2008) Human colonic microbiota associated with diet, obesity and weight loss. Int $\mathrm{J}$ Obes (Lond) 32: 1720-1724

11. Cox LM, Blaser MJ (2013) Pathways in microbe-induced obesity. Cell Metab 17: 883-894.

12. Parekh PJ, Arusi E, Vinik Al, Johnson DA (2014) The Role and Influence of Gut Microbiota in Pathogenesis and Management of Obesity and Metabolic Syndrome. Front Endocrinol (Lausanne) 5: 47.

13. Carey HV, Walters WA, Knight R (2013) Seasonal restructuring of the ground squirrel gut microbiota over the annual hibernation cycle. Am J Physiol Regu Integr Comp Physiol 304: R33-R42.

14. Kurtz CC, Carey HV (2007) Seasonal changes in the intestinal immune system of hibernating ground squirrels. Dev Comp Immunol 31: 415-428.

15. Sonoyama K, Fujiwara R, Takemura N, Ogasawara T, Watanabe J, et al. (2009) Response of gut microbiota to fasting and hibernation in Syrian hamsters. App Environ Microbiol 75: 6451-6456. 